\title{
Prevalence of maxillary and mandibular physiological space in the primary dentition
}

\author{
Felisia Flaviana Megan ${ }^{1}$, Niekla Survia Andiesta ${ }^{2}$, Ratna Indriyanti ${ }^{1}$, Arlette Suzy \\ Puspa Pertiwi Setiawan ${ }^{1 *}$ \\ ${ }^{1}$ Department of Pediatric Dentistry, Faculty of Dentistry Universitas Padjadjaran, Indonesia \\ ${ }^{2}$ Children and Community Oral Health Division, School of Dentistry International Medical University, \\ Malaysia
}

\section{ABSTRACT}

Introduction: Physiological space is the space between maxillary and mandibular primary central incisors as well as maxillary and mandibular primary lateral incisors that occur during primary dentition period. The absence of physiological space will lead the crowded of permanent dentition due to discrepancy of the size of tooth and jaw. The objective of this study was to evaluate and analyse the prevalence of physiological space of maxillary and mandibular during primary dentition period. Methods: The type of research was a descriptive survey technique. The study was conducted at the Early Childhood Education (PAUD) in Bandung City throughout January-March 2017. The study population was children aged 3-5 years. Multistage cluster sampling used to choose subjects based on the division of the area from the city area to obtain the desired population. The data used were primary data obtained by examining the existence of a gap with a gap width indicator that is used as a benchmark of at least $0.5 \mathrm{~mm}$ with the help of WHO probe tool. Data were collected, processed and analysed using the SPSS (Statistical Package for Social Sciences) version 20. Results: A total of 65 out of 97 subjects had physiological space in their first dentition period. From 97 study subjects (100\%) examined, 44 children (45.36\%) had maxillary physiological space, and 53 children (54.64\%) did not have maxillary physiological space. In 97 research subjects $(100 \%)$ there were also 48 children $(49.48 \%)$ having physiological space in the lower jaw, and 49 children $(50.52 \%)$ did not have physiological space in the lower jaw. Conclusion: Prevalence of the maxillary and mandibular physiological space in the primary dentition period of children in the city of Bandung are $67.01 \%$.

Keywords: Physiological space, primary dentition period.

P-ISSN 1979-0201, e-ISSN 2549-6212; Available from: http://jurnal.unpad.ac.id/pjd/article/view/19317

DOI: $10.24198 /$ pjd.vol31no1.19317

Submission: Nov 14, 2018; Accepted: Mar 16, 2020; Published online: Mar 31, 2020

"Corresponding author: Arlette Suzy Puspa Pertiwi Setiawan, Department of Pediatric Dentistry, Faculty of Dentistry Universitas Padjadjaran, Indonesia. Jalan Sekeloa Selatan I, Bandung, West Java, Indonesia, 40132. Phone: +6281395309191; Email: arlette.puspa@fkg.unpad.ac.id 


\section{INTRODUCTION}

In the primary dentition, space between teeth has a role in the eruption of permanent teeth, which can prevent crowding, and presents in a person's normal occlusion. ${ }^{1}$ There are two types of space found in the primary dentition period, namely primate space and physiological space. Physiological space/secondary space/ developmental space is the space found between incisor teeth. ${ }^{2}$ Canine relations, overjet, and overbite were assessed using the Foster and Hamilton criteria. Spacing conditions were registered according to Kisling and Krebs criteria. The prevalence of a space between two teeth varies between ethnicities, ranging from $42 \%$ to $98 \% .^{3}$

The presence of gap between incisors is frequently found in primary teeth occlusion. ${ }^{4}$ Space between teeth more commonly found in men than women. ${ }^{2}$ However, the space between central incisors is more commonly found in African-American female children. ${ }^{5}$ The visible width of the incisors ranges from 0-8 $\mathrm{mm}$ with an average of $4 \mathrm{~mm}$ in the maxilla, and $1-7 \mathrm{~mm}$ with an average of $3 \mathrm{~mm}$ in the mandible. ${ }^{6}$ The physiological space closes spontaneously when the permanent canines have erupted. ${ }^{7}$ Lack of space in the primary dentition can lead to the risk of crowding in the permanent dentition. Deciduous teeth begin with eruption of central mandibular incisors and end with the eruption of permanent first molars. The position of deciduous teeth will stabilise after tooth \#20 has erupted completely.

No research regarding the prevalence of physiological space in the primary dentition period of children in the city of Bandung has been conducted until the present time, even though physiological space is one of the determining factors for the presence or absence of crowding in the permanent teeth composition. Physiological space as a normal characteristic in the occlusion of the primary dentition is also not shown in every child. Therefore, we were interested in researching how many children had minimum physiological space width of $0.5 \mathrm{~mm}$ (according to diameter the tip of the WHO probe) within a sample of children aged 3-5 years in Bandung City. The purpose of this study was to determine and analyse the prevalence of maxillary and mandibular physiological space in the primary dentition period.

\section{METHODS}

The research was descriptive survey. The study was conducted at the Early Childhood Education (PAUD) in Bandung City throughout January-March 2017. The study population was children aged 3-5 years old. This age period was taken as one of the criteria of the research object due to the complete primary teeth composition at that age, and in a proper functional position.

The sampling technique was multistage cluster sampling. The subjects were taken based on a division of the area from the city to the desired population. The data used were primary data obtained by examining the existence of a gap with a gap width indicator that is used as a benchmark of at least $0.5 \mathrm{~mm}$ with the help of WHO probe tool. The WHO probe is a device used to localise, measure, mark pockets, and estimate pocket configurations on each side of the tooth, and established as the WHO standard size. The probe was placed in the gap between the central incisors and/or between the central incisors and lateral incisors, near the gingival area.

The study was conducted after gaining ethical approval with the registration number of 456/UN6.C10/PN/2017. The researchers then determined the sample at the chosen research location, gave informed consent, prepared tools and materials, as well as an examination sheet. Data were collected, processed, and analysed using the SPSS (Statistical Package for Social Sciences) version 20 software. The results of the study will be presented in the prevalence table and descriptive statistics to compare the prevalence of the maxillary and mandible physiological space in the children at Bandung City.

\section{RESULTS}

The study was conducted on 97 children who met the criteria and were registered in 6 Early Childhood Education (PAUD) in the city of Bandung consisted of 53 girls and 44 boys.

Data presented in Table 1 shows that out of 97 children who were the subjects of the study $(100 \%)$, there were 13 children $(13.40 \%)$ aged 3 
years, 29 children (29.90\%) aged 4 years, and 55 children (56.70\%) aged 5 years old.

Table 1. Distribution of research subjects based on age

\begin{tabular}{ccc}
\hline Age & F & $\%$ \\
\hline 3 years old & 13 & 13.40 \\
4 years old & 29 & 29.90 \\
5 years old & 55 & 56.70 \\
\hline Total & 97 & 100 \\
\hline
\end{tabular}

The results in Table 2 shows that 65 children (67.01\%) had physiological space, while 32 children (32.99\%) did not have physiological space.

Table 2. Prevalence of maxillary and mandibular physiological space on the 3-5 years old children

\begin{tabular}{ccc}
\hline Physiological space & Prevalence & $\%$ \\
\hline Exist & 65 & 67.01 \\
Unexist & 32 & 32.99 \\
\hline Total & 97 & 100 \\
\hline
\end{tabular}

Table 3 shows that 44 children (45.36\%) had maxillary physiological space, and 53 children (54.64\%) did not have maxillary physiological space. Also, there were 48 children (49.48\%) with mandibular physio-logical space in the lower jaw, and 49 children (50.52\%) did not have any.

Table 3. Distribution of maxillary and mandibular physiological space frequency on the 3-5 years old children based on the jaw position

\begin{tabular}{ccccc}
\hline \multirow{2}{*}{ Physiological space } & \multicolumn{2}{c}{ Maxillary } & \multicolumn{2}{c}{ Mandible } \\
\cline { 2 - 5 } & $\mathrm{N}$ & $\%$ & $\mathrm{~N}$ & $\%$ \\
\hline Exist & 44 & 45.36 & 48 & 49.48 \\
Unexist & 53 & 54.64 & 49 & 50.52 \\
\hline Total & 97 & 100 & 97 & 100 \\
\hline
\end{tabular}

The results of the study described in Table 4 shows that from 53 girls (100\%) examined, 36 girls $(67.92 \%)$ had physiological space, and 17 girls $(32.08 \%)$ did not have physiological space. Also, from 44 boys (100\%) examined, 29 of them (65.90\%) had physiological space, and 15 (34.10\%) did not have physiological space.

Out of 13 children aged 3 years old examined, 10 children (76.92\%) had physiological space, and 3 chil-dren (23.08\%) did not have physiological space. From 29 children aged 4 years old, 15 children (51.72\%) had physiological space, and 14 children (48.28\%) did not have physiological space. Out of 55 children aged 5 years old as the research subjects, 40 children $(72.73 \%)$ had physiological space, and 10 children (27.27\%) did not have physiological space (Table 5 ).

Table 4. Distribution of maxillary and mandibular physiological space frequency based on sex

\begin{tabular}{ccccc}
\hline \multirow{2}{*}{ Physiological space } & \multicolumn{2}{c}{ Female } & \multicolumn{2}{c}{ Male } \\
\cline { 2 - 5 } & $\mathrm{N}$ & $\%$ & $\mathrm{~N}$ & $\%$ \\
\hline Exist & 36 & 67.92 & 29 & 65.90 \\
Unexist & 17 & 32.08 & 15 & 34.10 \\
\hline Total & 97 & 100 & 97 & 100
\end{tabular}

Table 5. Distribusi Frekuensi Physiological Space Berdasarkan Usia

\begin{tabular}{ccccccc}
\hline $\begin{array}{c}\text { Physiological } \\
\text { space }\end{array}$ & \multicolumn{2}{c}{ 3-years-old } & \multicolumn{2}{c}{ 4-years-old } & \multicolumn{2}{c}{ 5-years-old } \\
\cline { 2 - 7 } & $\mathrm{N}$ & $\%$ & $\mathrm{~N}$ & $\%$ & $\mathrm{~N}$ & $\%$ \\
\hline Exist & 10 & 76.92 & 15 & 51.72 & 40 & 72.73 \\
Unexist & 3 & 23.08 & 14 & 48.28 & 15 & 27.27 \\
\hline Total & 13 & 100 & 29 & 100 & 55 & 100 \\
\hline
\end{tabular}

\section{DISCUSSION}

Based on the results obtained in Table 3, 65 children $(67.01 \%)$ had physiological space in their primary dentition period. This result shows that most children have normal characteristics in their primary dentition period, with more than half of the children had physiological space. These results were consistent with the theory stated that one of the typical characteristics in the primary dentition period is the presence of diastema, and one of the diastemata is physiological space. ${ }^{2}$ In 32 children (32.99\%) with no physiological space, the risk of crowding during mixed or permanent dentition periods increases, because physiological space is useful as a provider of space for the eruption of permanent incisors. Physiological space is also a determining factor in the development of the normal permanent dental occlusion.

Results of research in India showed that the prevalence of maxillary physiological space was $50.9 \%$ and $46.7 \%$ found in the mandible. ${ }^{9}$ Prevalence of the physiological space varies significantly between ethnicities, ranging from $42 \%$ to $98 \% .^{2}$ The results of the study described in Table 4 show that 44 children $(45.36 \%)$ had maxillary physiological space and 48 children $(49.48 \%)$ had 
mandibular physiological space. The descriptions provide information that physiological space is more often found in the mandible compared to the maxilla. Another study of Indian children in Udaipur also found that physiological space was found more in the mandible than in the maxilla, with a percentage ratio of $57 \%$ to $60 \% .{ }^{10}$ Other theories also suggested that physiological space is typical in the primary dentition period with a percentage of $82.4 \%$ in the maxilla and $74.8 \%$ in the mandible. ${ }^{8}$

The amount of space needed for the eruption of permanent incisors is approximately $7.6 \mathrm{~mm}$ in the maxilla, one of which is obtained through an interdental spacing of $3 \mathrm{~mm}$ in the maxilla. ${ }^{6}$ Physiological space is the type of interdental spacing with the largest gap size, which is 2.86 $\mathrm{mm}$ in the maxilla and $3.08 \mathrm{~mm}$ in the mandible hence the maxillary and mandibular physiological space is needed to com-pensate the space for the upcoming permanent incisors.

The results in Table 4 show that of 97 children aged $3-5$ years $(100 \%)$ examined, 53 children $(54.64 \%)$ did not have maxillary physiological space and 49 children (50.52\%) did not have physiological space in the lower jaw. This result shows that more than half of the samples which were chosen randomly did not have both maxillary and mandibular physiological space. The absence of space will lead to the problem of malocclusion, which is crowding. The primary cause of malocclusion is divided into two, namely genetic or hereditary factors and environmental factors. Genetic factors that can be the cause of the absence of space are the vast imbalance of teeth with jaws where the size of the tooth is bigger or tightly equal with the size of the jaw.

Physiological space as one of the determinants of malocclusion can also be influenced by differences in the pattern of babysitting with a history of breastfeeding and using a pacifier. Bowden et al. stated that the habit of using a pacifier would cause malocclusions such as reduced jaw width which results in the absence of space in the anterior teeth. ${ }^{12}$

The results in Table 5 show that of 53 girls $(100 \%)$ who met the criteria, 36 of them $(67.92 \%)$ had physiological space, while in all 44 boys $(100 \%)$ who met the criteria, 29 children $(65.90 \%)$ had physiological space. These results showed that physiological space was found more in girls than in boys. It was also found in African American children that the space between incisors was more commonly existed in girls than in boys. ${ }^{5}$

Physiological space is more commonly found in women due to the eruption of primary incisors. The eruption of deciduous teeth in girls is 4 to 5 months faster than in boys. ${ }^{13}$ However, in the present study, this factor was not included. Baghdady reported that the mean eruption time of maxillary incisors in wom-en was faster than in men. ${ }^{15}$ Khamrco also found that mandibular incisor teeth erupted earlier than mandibular incisors and this phenomenon was found mostly in girls. ${ }^{16}$ The faster incisor eruption time in women can be one of the causes of the appearance of physiological space is also more quickly seen in girls. ${ }^{16}$ Another cause of the more significant percentage of physiological space in girls is the mesiodistal size of the female permanent incisors which is found to be higher than the boys; thus the gap needed must be higher. ${ }^{14}$

The results also show that the frequency distribution of physiological space in 3-yearsold children was $76.92 \%, 51.72 \%$ in 4 -years-old children, and $72.73 \%$ in 5 -years-old children. These results indicated that the physiological space was mostly found in children aged 3 years old and decreased at the age of 4 years old. Physiological space between incisors is often found at an early age and widens as the child grows, and the alveolar process enlarges. ${ }^{9}$

Physiological space was found to be increased in children aged 5 years old, but the percentage was still smaller than the 3 years old children. This percentage can be caused by an impulse of a permanent central incisor that will erupt at the age of 6 , thus closing the physiological space in the jaw. While the percentage of physiological space that increases at the age of 5 years compared to at the age of 4 years can be caused by the increase in the size of the jaw along with age, but the size of the incisors does not change hence the number of physiological space found is more.

The gap between the teeth will widen along with the growth and development of the jaw. That means along with the age of the child, the size of the space also widens. The results of the present study show a decrease in the frequency distribution and prevalence of the physiological 
space at the 3-years-old and 4-years-old. This result occurred because the study sample taken randomly with different ages. The evidence which showed that the physiological space would widen along with age was not found because the growth and development from the age of 3 years old to 5 years old are different for every individual.

\section{CONCLUSION}

Prevalence of the maxillary and mandibular physiological space in the primary dentition period of children in the city of Bandung are $67.01 \%$.

\section{REFERENCES}

1. Ribeiro JS, Ambrosio AR, dos Santos-Pinto A, Shimizu IA, Shimizu RH. Evaluation of transverse changes in the dental arches according to growth pattern: A longitudinal study. Dental Press J Orthod. 2012;17(1):6673. DOI: $10.1590 /$ S2176-94512012000100010

2. Vegesna M, Chandrasekhar R, Chandrappa V. Occlusal Characteristics and Spacing in Primary Dentition: A Gender Comparative Cross-Sectional Study. Int Sch Res Not. 2014;17. DOI: $10.1155 / 2014 / 512680$

3. Vinay S, Keshav V, Sankalecha S. Prevalence of Spaced and Closed Dentition and its Relation to Malocclusion in Primary and Permanent Dentition. Int J Clin Pediatr Dent. 2012;5(2):98100. DOI: $10.5005 /$ jp-journals-10005-1144

4. Millet DT, Welbury R. Orthodontics and paediatric dentistry. $2^{\text {nd }}$ ed. New York: Churchil and Linvinstone Elsevier; 2010. p. 212.

5. Owais Al, Shaweesh M, Abu Alhaija ESJ. Maximum occusal bite force for children in different dentition stages. Eur J Orthod. 2013;35(1):427-33. DOI: 10.1093/ejo/cjs021

6. Tandon S. Textbook of pedodontics. Hyderabad, New Delhi: Paras Medical Publisher; 2009. 209 p.

7. Abu-Hussain M, Watted N. Maxillary midline diastema-aetiology and orthodontic treatment-Clinical review. IOSR J Dent Med
Sci. 2016;15(6):116-30. DOI: 10.9790/0853150602116130

8. Abuaffan AH, Abd-Alrahman RM. Occlusal Characteristics of Primary Dentition in Sudanese Children in Khartoum State. Brazilian Dent Sci. 2014;17(2):3-9. DOI: 10.14295/ bds.2014.v17i2.945

9. Lochib S, Indushekar KR, Saraf BG, Sheoran $N$, Sardana D. Occlusal characteristics and prevalence of associated dental anomalies in the primary dentition. J Epidemiol Glob Health. 2015;5(2):151-7. DOI: 10.1016/j. jegh.2014.07.001

10. Hegde S, Panwar S, Bolar DR, Sanghavi MB. Characteristics of occlusion in primary dentition of preschool children of Udaipur, India. Eur J Dent. 2012;6(1):51-5.

11. Janiszewska-Olszowska J, Stepien P, Syrynska M. Spacing in deciduous dentition of Polish children in relation to tooth size and dental arch dimensions. Arch Oral Biol. 2009;54(5):397402. DOI: $10.1016 /$ j.archoralbio.2008.12.008

12. Peres KG, Chaffee BW, Feldens CA, Flores-Mir C, Moynihan P, Rugg-Gunn A. Breastfeeding and Oral Health: Evidence and Methodological Challenges. J Dent Res. 2018;97(3):251-8. DOI: $10.1177 / 0022034517738925$

13. Almonaitiene R, Balciuniene I, Tutkuviene J. Standards for permanent teeth emergence time and sequence in Lithuanian children, residents of Vilnius city. Stomatol Balt Dent Maxillofac J. 2012;14(3):93-100.

14. Muhammad NO, Ali DA, Kareem FA, Noori AJ. Timing of primary tooth emergence of a group of Sulaimani Kurdish children. IOSR J Dent Med Sci. 2015;14(10):72-6. DOI: 10.9790/0853141077276

15. Baghdady VS, Ghose LJ. Eruption Time of Primary Teeth in Iraqi Children. Community Dent Oral Epidemiol. 1981;9(5):245-6. DOI: 10.1111/j.1600-0528.1981.tb00338.x

16. Khamrco TY, Qasim AA. Time and order of eruption of primary teeth for children in Mosul City, Iraq. AlRafidain Dent J. 2002; 2(3): 32740. 